\section{A imigração haitiana e a criminalidade no município de Manaus}

\section{HAITIAN IMMIGRATION AND CRIME IN THE CITY OF Manaus}

\author{
Alexandre dos Santos Tamer * \\ Valmir César Pozzetti **
}

Resumo: Este artigo abordou a relação entre a criminalidade registrada no Município de Manaus no período de Janeiro de 2010 e Maio de 2013 e a imigração de Haitianos ocorrida à partir de 2010, decorrente do terremoto que atingiu aquele país. $\mathrm{O}$ entrecruzamento de dados entre raça, crime e violência justificou-se, pois este movimento imigratório desencadeou reações na sociedade manauara, decorrentes do de fatores diversos, tais como preconceito social, racismo e xenofobia. Foram coletados os dados da criminalidade no período analisado e extraídos os registros que possuíam vítimas e/ou autores haitianos. Foi identificado que os haitianos foram vítimas na quase totalidade dos registros encontrados, e que nenhum haitiano cometeu os crimes de maior potencial ofensivo, no período analisado.

Palavras-chave: Imigração. Haitianos. Preconceito. Violência. Criminalidade. Xenofobia.

* Alexandre dos Santos Tamer, Mestrando do Programa de Pós-Graduação em Segurança Pública, Cidadania e Direitos Humanos da UEA- Universidade do Estado do Amazonas. Email: tamer.brazil@gmail.com ** Valmir César Pozzetti, Professor Adjunto do Mestrado em Direito Ambiental da Universidade do Estado do Amazonas

e Professor Adjunto do Mestrado em Controladoria e Contabilidade da Universidade Federal do Amazonas; Mestre em Direito Ambiental e Doutor em Direito comparado pela Universitè de Limoges/França. E-mail: v_pozzetti@hotmail. com
Abstract: This article addressed the relationship between recorded crime in the city of Manaus in the period January 2010 to May 2013 and the immigration of Haitians occurred starting from 2010 due to the earthquake that hit that country. The interchange of data between race, crime and violence was justified, because this immigration movement triggered reactions in society manauara, resulting from several factors, such as social prejudice, racism and xenophobia. Data were collected from the crime in the period analyzed and extracted the records that had victims and / or perpetrators Haitians. It was identified that the Haitians were victims in almost all records found, and that no Haitian committed crimes potentially offensive in the period analyzed.

Keywords: Immigration. Haitians. Prejudice. Violence. Crime. Xenophobia. 


\section{INTRODUÇÃO}

O Haiti teve um grande terremoto em 2010, noticiado mundialmente, e uma epidemia de cólera em 2011, que desencadearam tragédia e miséria naquele país. Iniciou-se à partir daí uma onda de imigração para o Brasil. A economia brasileira era bastante conhecida, divulgada pela mídia, e vista pelos haitianos como uma oportunidade.

Um fluxo maciço de imigrantes haitianos atravessou pela fronteira norte brasileira. A cidade de Brasileia, no Acre, representa bem essa situação. É possível encontrar nas suas ruas, haitianos vagando, sem direção e sem emprego. Segundo dados da Polícia Federal, estima-se que até maio de 2013, aproximadamente $7 \mathrm{mil}$ haitianos adentraram as fronteiras brasileiras, buscando melhores condições de vida no Brasil. Passaram por Manaus, também segundo a Polícia Federal, cerca de 4.500 haitianos.

Manaus, com uma população de 1.802.014 habitantes em 2010 segundo IBGE, recebeu uma massa populacional de haitianos, que, em sua grande maioria, apenas passou por Manaus em busca de outras cidades. Segundo os dados da polícia federal, $84 \%$ dos haitianos que passaram pelo serviço de imigração são homens e $16 \%$ de mulheres. Destes imigrantes, $67 \%$ eram casados e $33 \%$ solteiros, e todos com escolaridade baixa, dividindo-se em 33\% com curso técnico, $21 \%$ com ensino médio incompleto e $16 \%$ com ensino fundamental incompleto.

Considerando a escolaridade deficitária da maioria dos imigrantes haitianos, aliada à escassez de empregos e baixos salários oferecidos na cidade de Manaus, chega-se ao cerne principal que motivou o artigo: qual a parcela de imigrantes haitianos que adentrou na criminalidade, contribuindo para o aumento dos índices criminais na cidade de Manaus? Fatores como preconceito social, racismo e xenofobia desencadearam uma série de reações da população, e que culminaram com discursos inflamados, artigos de jornais, entre outros. Hoje, o que ainda resta destes fatores aponta para um aumento na criminalidade, tendo os Haitianos como personagens centrais.

Atualmente o Conselho Nacional de Imigração (CNIg), órgão ligado ao Ministério do Trabalho, está concedendo vistos de trabalho aos cidadãos haitianos que chegaram ao Brasil. A concessão destes vistos é uma medida alternativa e de proteção do País, já que a legislação brasileira e as convenções internacionais não reconhecem como refúgio, aquele relacionado a desastres naturais ou fatores climáticos. 
O objetivo deste artigo é analisar os dados de registros de ocorrências nas delegacias de Manaus, no período de Janeiro de 2010 até Maio de 2013, e avaliar a parcela destes registros que contêm a participação de haitianos, como vítimas e/ou autores.

O artigo divide-se em seis seções, incluída a parte introdutória na seção um. Na seção dois apresenta-se a fundamentação teórica, onde se examinam a participação da mídia no aumento da sensação de insegurança, a internacionalização dos direitos fundamentais, os "refugiados ambientais" e a negativa em caracterizá-los como refugiados, a solução brasileira para os imigrantes haitianos, abordagem sobre o preconceito e a fundamentação da desigualdade social como causa do incremento da criminalidade. $\mathrm{Na}$ seção três descrevem-se a metodologia e os dados aplicados para a realização da pesquisa. Na quarta parte do trabalho analisam-se os resultados e as etapas da pesquisa, destacando, sintetizando, analisando os principais pontos observados. Na quinta parte apontam-se as conclusões do estudo, e, por fim na sexta parte localiza-se a bibliografia utilizada.

A metodologia utilizada nesta pesquisa, foi a do método hipotéticodedutivo e quantitativo, já que foi precedida do estudo das teorias existentes na bibliografia sobre o assunto, efetuando-se, posteriormente, comparação dessa literatura com o que foi observado. Foram avaliados os dados da criminalidade no município de Manaus, explicitando os crimes cometidos por Haitianos no período entre Janeiro de 2010 e Maio de 2013.

\section{EFETIVAÇÃO DE DIREITOS AOS REFUGIADOS HAITIANOS}

A violência, por ser um tema complexo, possui diferentes definições. Alba Zaluar (1999, p.32) recorre à etimologia do termo "violência", do latim "violentia" e que remete a vis (força, vigor, emprego de força física). E completa dizendo que essa força é chamada de violência quando ultrapassa um limite ou perturba acordos e regras que ordenam as relações, adquirindo carga negativa ou maléfica.

O crime possui várias definições. Segundo Adorno (2002, p. 88), crime é um conceito jurídico e relaciona-se à violência codificada nas leis penais. $\mathrm{E}$ acrescenta:

Sabe-se, porém, que nem todo fenômeno socialmente percebido como violento é categorizado como crime. Do mesmo modo, há modalidades de 
violência que, embora codificadas como crime, não encontram adequado enquadramento na legislação penal correspondente. Por exemplo, graves violações de direitos humanos não raro enquadrados como crime comum.

A mídia age divulgando a violência, estimulando, assim, o temor na sociedade. Sobre tal questão, Adorno (2002, p. 100) esclarece:

Trata-se de um infindável número de situações, em geral envolvendo conflitos entre pessoas conhecidas, cujo desfecho acaba muitas vezes até acidental e inesperadamente, na morte de um dos contendores. Compreendem conflitos entre companheiros e suas companheiras, entre parentes, entre vizinhos, entre amigos, entre colegas de trabalho, entre conhecidos que frequentam os mesmos espaços de lazer, entre pessoas que se cruzam diariamente nas vias públicas, entre patrões e empregados, entre comerciantes e seus clientes. [...] No mais das vezes, revelam quanto o tecido social encontra-se sensível as tensões e confrontos que, no passado, não pareciam convergir tão abruptamente para um desfecho fatal.

Vê-se, então, que a mídia divulga de forma efusiva notícias ligadas à violência. Entretanto, é necessário cuidado, pois nem sempre a mídia consegue interpretar com coerência e precisão os fatos jurídicos.

\subsection{A Internacionalização dos direitos fundamentais e os direitos dos haitianos}

Os direitos fundamentais não devem ser restritos ao Estado. Próprio da natureza humana, eles transcendem o próprio Estado, atingindo o âmbito internacional. Assim, por exemplo, qualquer atentado a um individuo que não seja nacional de um determinado país, fora do limite geográfico da soberania do seu estado mãe, deve ser coibido e interpretado como atentado aos direitos humanos do cidadão.

O que se quer dizer com isso é que, o direitos fundamentais, os direitos à dignidade da pessoas humana deve ser respeitado e defendido, mesmo que esse ser humano não esteja em sua pátria. É um dever/obrigação do estados e um direito do cidadão, tratar e ser tratado com dignidade e ter respeitados todos os seus direitos fundamentais.

Sobre a internacionalização dos direitos humanos, Alves (1994, p. 5) assim se posiciona: 
As construções internacionais existentes ultrapassaram as noções tradicionais de soberania e interesses. Ao subscrever uma convenção internacional sobre direitos humanos, ao participar de organizações regionais sobre o assunto, ou conforme é hoje interpretação corrente, pelo simples fato de integrar-se às Nações Unidas, para quem a declaração universal dos direitos humanos, se não era originalmente compulsória, tem força de jus cogens como direito costumeiro. Os Estados abdicam soberanamente de uma parcela da soberania, em sentido tradicional, obrigando-se a reconhecer o direito da comunidade internacional de observar e, consequentemente, opinar sobre sua atuação interna, sem contrapartida de vantagens concretas.

A dignidade da pessoa humana, princípio inserido no inciso III do artigo $1^{\circ}$ da Constituição, vigora como princípio fundamental, e do qual decorrem as demais regras jurídicas infraconstitucionais, que determinam a obrigação do Estado quanto à promoção e defesa destes direitos fundamentais. Sarlet (2006, p.66) assim comenta:

A Dignidade da Pessoa Humana enquadra-se como princípio jurídico constitucional fundamental, pois, na verdade, não obstante o nosso ordenamento jurídico constitucional não tenha incluído a dignidade da pessoa humana no rol dos Direitos e Garantias Fundamentais, elevou-se este valor ao status normativo de princípio constitucional devidamente insculpido no inciso III do artigo $1^{\circ}$, garantindo-lhe, desta forma, um grau de normatividade e um nível de proteção que justifica e exige sua promoção, em razão do que desnecessário que ele constasse positivado para que, viesse a ser respeitado na condição de valor inerente a toda e qualquer pessoa humana; afinal, na medida em que esta existe, aquele, deve, há de ser protegido pelo Direito.

Vê-se, portanto, que a dignidade da pessoa humana é um dos fundamentos da República Federativo do Brasil. Logo, deve a república perseguir esse fundamento e fazê-lo cumprir. Entretanto, como o texto constitucional não faz menção de que somente os brasileiros terão esse direito e sim, que é um fundamento da república, tanto brasileiros como estrangeiros em permanência e provisoriamente no Brasil, terão o direito de ser tratados de forma digna.

\subsection{O problema em caracterizar os Haitianos como refugiados}

Se os haitianos fossem considerados refugiados, é sabido que teriam direto a um sistema protetivo internacional e com objetivos estritamente humanos. 
A Declaração Universal dos Direitos do Homem, de 1948, em seu artigo XXV, garante a todos os seres humanos um nível de vida suficiente para assegurar sua saúde, o seu bem-estar e o de sua família, especialmente nas questões referentes à alimentação, moradia, assistência médica, educação, o direito à seguro em caso de desemprego, doença, invalidez, viuvez, velhice ou outros casos de perda dos meios de subsistência em circunstâncias fora de seu controle.

Nesse sentido Varella (2009, p. 198) comenta sobre as condições para os refugiados:

O refúgio possui lastro em perseguições a um grupo de indivíduos em função de sua raça, religião, nacionalidade ou opção política, havendo como elemento subjetivo o temor de perseguição em seu país, além da ameaça de um julgamento injusto, sem o devido processo legal.

E, mencionando o Estatuto dos Refugiados, Soares (2004, p. 395) comenta:

A citada Convenção sobre o Estatuto dos Refugiados, como se disse, adotada em Genebra em 28/7/1951, constitui a Magna Carta dos refugiados e foi elaborada a partir de projeto elaborado sob a égide do Acnur; sua maior importância advém do fato de caracterizar-se como documento normativo multilateral, que tipifica o status de refugiado, institui seus direitos subjetivos, por meio de um arrolamento deles, institui obrigações aos Estados-partes de respeitarem tal status.

Logo, este estatuto regulamenta o Alto Comissariado das Nações Unidas para refugiados (ACNUR), como órgão único da ONU responsável pela implementação dos direitos dos refugiados, e por determinar as obrigações dos Estados-partes, como por exemplo, a adequação de seus ordenamentos jurídicos ao presente documento.

$\mathrm{O}$ atual posicionamento da ACNUR sobre os refugiados de desastres naturais, segundo Ramos (2011), dá-se pela prevalência em relação à Convenção relativa ao Estatuto dos Refugiados de 1951, ao Protocolo lançado pelo governo das Ilhas Maldivas juntamente com a Organização das Nações Unidas (ONU), a Organização Mundial da Saúde (OMS) e o Fundo das Nações Unidas para a Infância (Unicef), e cujos objetivos seriam a salvação, proteção e reabilitação das vidas de pessoas deslocadas interna ou externamente de ambientes ou habitats que foram, são ou serão destruídos por desastres naturais (força maior), ou por impactos ambientais provocados pelo homem. Tal protocolo 
assegura direitos básicos como abrigo, comida, água potável, medicamentos e assistência médica, mediante a criação de um fundo de adaptação a impactos ambientais.

O Brasil, como um Estado humanitário, apoiador e signatário dos princípios protetivos aos direitos fundamentais e coletivos, vem prestando assistência humanitária aos haitianos que ilegalmente adentraram em nossas regiões fronteiriças, como ainda em algumas cidades do estado do Acre (Brasiléia, Assis Brasil e Epitaciolândia) e no estado do Amazonas (Tabatinga e Manaus). São inúmeros os que chegam, acometidos pela fome, sede e outras necessidades.

Idoeta (2012, p. 23), refere-se à controvérsia gerada pelo controle migratório de haitianos no Brasil, ressaltando as palavras de Luiz Paulo Barreto, ex-Ministro da Justiça: "Nossa preocupação não é tanto com o número de imigrantes, mas com a forma como vêm, por intermediários ilegais pela floresta. Soubemos de casos de estupro, de roubos, de violência contra os haitianos. O Brasil não tem essa tradição".

Sobre a proteção aos estrangeiros em nosso Estado, Rezek (2007, p. 194) traz o seguinte entendimento:

Qualquer estrangeiro encontrável em seu território - mesmo que na mais fugaz das situações, na zona de trânsito de um aeroporto - deve o Estado proporcionar a garantia de certos direitos elementares da pessoa humana: a vida, a integridade física, a prerrogativa eventual de peticionar administrativamente ou requerer em juízo, o tratamento isonômico em relação a pessoas de idêntico estatuto.

Neste sentido a Constituição Brasileira confere legitimidade a Rezek :

art. $4^{\circ}$. A República Federativa do Brasil rege-se nas suas relações internacionais pelos seguintes princípios:

I- (...) omissis

II - prevalência dos direitos humanos.

E o nosso ordenamento jurídico rege-se pelo respeito ao princípio do non-refoulement, advindo da Declaração de Cartagena (1984) e entendido como o "princípio da não devolução". Este princípio veda qualquer forma de repúdio aos pretendentes de refúgio nas fronteiras dos Estados, considerando 
os direitos fundamentais. Por esse motivo, o Brasil não pode devolver um refugiado de catástrofe, como os haitianos.

A convenção de 1951, que versa sobre o Estatuto dos Refugiados, determina aos Estados contratantes, a não discriminação quanto à raça, à religião ou ao país de origem.

Também assegura aos refugiados na cláusula 22 a educação pública, e na cláusula 23 a igualdade e o mesmo tratamento dado aos nacionais na assistência e socorros públicos. A cláusula $26^{\mathrm{a}}$ diz que cada Estado-parte dará aos refugiados o direito de escolher o local do seu território para fixar sua residência e de circular livremente.

Na cláusula 33 fica proibida, aos Estados, a expulsão e o rechaço de quaisquer refugiados para as fronteiras dos territórios cuja vida ou liberdade estejam ameaçadas em decorrência de raça, religião, nacionalidade, grupo social ou opiniões políticas.

Caracteriza-se assim o princípio internacional do "non-refoulement", englobando todos os Estados, independente da ratificação ao referido Estatuto dos Refugiados.

Ainda nesta linha de raciocínio, sobre o Estatuto dos Refugiados, Del'Olmo (2009, p. 276) discorre:

A Convenção da ONU Relativa ao Estatuto dos Refugiados, assinada em Genebra em 1951, conceituou "refugiado" como a pessoa que, temendo ser perseguida em seu país por motivos de raça, religião, nacionalidade, grupo social ou opiniões políticas, dele se afasta e a ele evita retornar, perdendo a proteção do mesmo Estado.

A doutrina internacional vem indicando a possibilidade de serem considerados refugiados aquelas pessoas que residiam em locais que sofreram desastres naturais, alterações químicas, físicas e biológicas dos seus recursos, quando o ambiente torna-se inóspito à vida: os "refugiados ambientais".

Todavia, na prática, esta nova modalidade de refúgio tem sido rechaçado pelos Estados, que alegam sua soberania e a discricionariedade para negarem a concessão.

Nesse sentido, D’Adesky (2003, p. 193), pondera que:

O crescimento de fluxos migratórios mundiais vem ensejando crescentes recusas pelos Estados, notadamente quanto aos refugiados, em total afronta ao princípio da inclusão universal da cidadania, implicando à certos países 
um nacionalismo xenófobo, contrariando postulados consuetudinários de respeito à dignidade humana e à diversidade cultural. Tais nacionalismos extremistas repelem-se ao ideário de uma ordem internacional lastreada em axiomas principiológicos de paz, cooperação e solidariedade global, cuja materialização ocorre no reconhecimento destas coletividades em sua igualdade, independentemente de características étnicas e ideologias culturais e religiosas, efetivamente incluindo-as à determinada comunidade nacional.

Segundo a ACNUR, não há definição legal para refugiado ambiental, o que impede estes refugiados de receber assistência igualitária aos outros tipos de refugiados, como o direito às políticas públicas, asilo e auxílio financeiro.

Andrade (1996, p. 183) analisa a questão da seguinte forma:

O termo "refugiado" necessita ser "flexibilizado", vez que as definições jurídicas particularizadas para determinados grupos de refugiados mostraramse incapazes de lidar com o fenômeno, corroborado pelo fato deste tema estar inserido e destacado na agenda internacional, desde os primórdios da Liga das Nações. As relações internacionais contemporâneas provam que a necessidade da flexibilização das soluções para os refugiados, constitui a fórmula de sucesso em negociações, cujo negociado é o próprio homem, coletivamente qualificado.

Nos tempos atuais, a discricionariedade aliada à soberania dos Estados tornam-se um problema para o reconhecimento da condição de refugiados, principalmente quando se trata de questões ambientais. A circulação de pessoas entre os Estados não é garantida. Não há a aceitação deste contingente como refugiados de desastres naturais, tampouco o conceito é reconhecido.

Em decorrência, os Estados ignoram a concessão de direitos fundamentais a esses "refugiados ambientais", exclusivamente porque não há uma classificação jurídica internacionalmente aceita. Ou seja, os "refugiados ambientais" não se enquadram na condição de asilados, tampouco de refugiados, já que não há perseguição política, religiosa que assim o justifique, bem como não há nenhuma violação de seus direitos decorrente da nacionalidade, raça, ou condição social.

A ACNUR tem incentivado a prática do princípio do non-efoulement pelos Estados, apesar da ausência desta classificação jurídica. Este programa da ONU impede que os Estados enviem de volta os "refugiados de desastres naturais" ao Estado de origem, usando os conceitos de violação à sua dignidade 
humana. O princípio do non-refoulement está presente na Declaração de Cartagena, conforme segue:

Reiterar a importância e a significação do princípio de non-refoulement (incluindo a proibição da rejeição nas fronteiras), como pedra angular da proteção internacional dos refugiados. Este princípio imperativo respeitante aos refugiados deve reconhecer-se e respeitar-se no estado atual do direito internacional, como um princípio de "jus cogens". (ORGANIZAÇÃO DAS NAÇÕES UNIDAS, 1984)

\section{O BRASIL E A IMIGRAÇÃO HAITIANA}

O ordenamento jurídico nacional não configura a condição de refugiados aos que deixaram seus países por razões de ordem natural, como o terremoto que abateu o Haiti em 2010. A ausência de regulamentação de refugiado ambiental é proposital e um reflexo da preocupação dos Estados diante do aumento crescente das catástrofes naturais em todo o globo, que poderiam originar um movimento imigratório descontrolado em seus territórios.

A ACNUR (Alto Comissário das Nações Unidas para Refugiados) e o IMDH (Instituto Migrações e Direitos Humanos) realizaram em maio de 2012 o VIII Encontro Nacional das Redes de Proteção, enfocando os "Deslocamentos Humanos por Motivos Ambientais e Catástrofes Naturais". $\mathrm{Na}$ época foi discutida a situação dos Haitianos que imigraram para o Brasil após o terremoto de 2010. Andrés Ramírez, representante da ACNUR no Brasil disse:

Mais e mais pessoas são forçadas a fugir devido a razões que não são descritas na Convenção dos Refugiados de 1951. Eles não são migrantes no sentido típico, mas também não estão abarcados pelo regime de proteção dos refugiados. É importante que estejamos atentos às necessidades dessas pessoas que são deslocadas por desastres naturais. (ORGANIZAÇÃO DAS NAÇÕES UNIDAS, 2012).

A solução para os Haitianos partiu do CNIg (Conselho Nacional de Imigração), órgão vinculado ao Ministério do Trabalho: foram concedidos vistos humanitários, através da apresentação de passaporte e da certidão 
de antecedentes criminais, sem exigência de qualificação profissional ou contrato de trabalho no Brasil. Todavia o CNIg estabeleceu um prazo de cinco anos para os haitianos conseguirem emprego e residência, regularizando a sua situação no país. Os haitianos com o visto humanitário e autorizados a residir no Brasil têm os mesmos direitos civis que os brasileiros, ou seja, acesso a trabalho, saúde e educação. Este visto é novo e especial para o Haiti. Nenhum outro país já se beneficiou desta categoria especial de visto.

Neste sentido Godoy (2011, p. 63) refere-se ao visto humanitário da seguinte forma:

No que se refere ao tratamento conferido aos haitianos que solicitam refúgio no Brasil, o denominado "visto humanitário" é uma interessante ferramenta de proteção complementar e tal prática tem potenciais enormes a serem revelados [...] O "visto humanitário" concedido aos haitianos no Brasil pretende ser uma resposta complementar frente ao deslocamento de pessoas vítimas dos efeitos dos desastres naturais... Propõe-se que a devolução ao país de origem e as deportações em massa não sejam levadas a cabo, especialmente levando-se em conta a peculiar situação do Haiti, o dispositivo do artigo $7^{\circ}$ do Pacto Internacional dos Direitos Civis e Políticos e as obrigações gerais de Non-Refoulement contidas nos demais tratados internacionais do qual o país é parte.

Esta medida foi acordada com o Comitê Nacional para os Refugiados (Conare), e contou com o apoio de representantes da sociedade civil e do Alto Comissariado das Nações Unidas para Refugiados (ACNUR). Ela permite aos haitianos se estabelecer no Brasil, buscar emprego e ter os mesmos direitos de qualquer estrangeiro em situação regular. Segundo Paulo Sérgio de Almeida, presidente do CNIg, praticamente todos os haitianos declararam que possuíam uma profissão. As profissões mais recorrentes foram aquelas ligadas à construção civil.

Com a chegada dos imigrantes ao município de Manaus, a sociedade e o Estado tiveram que se adaptar à inserção de um grande contingente de pessoas na já caótica estrutura de serviços, de moradia e emprego. Enfrentaram xenofobia e preconceito.

Adorno (1995, p. 81) conclui que não somente a classe social, mas também o grupo racial é determinante no tratamento dispensado aos negros: 
A cor é poderoso instrumento de discriminação na distribuição da justiça. O princípio de eqüidade de todos perante as leis, independentemente das diferenças e desigualdades sociais, parece comprometido em face dos resultados alcançados.

Lopes Neto (2005, p. 168) assevera que:

A vítima do preconceito, tal qual ocorre no Bullying, é aquela que carrega consigo algum aspecto, uma característica predominante, que se torna uma marca identificadora de qualidade inferior. Estes aspectos do preconceito chegam a influenciar as próprias vítimas, fazendo com que se sintam responsáveis pelo próprio sofrimento. É possível que este fato seja determinante, quando, na maioria dos casos, a vítima decide não revidar as provocações ou que não procure ajuda por medo de retaliações e até mesmo por acreditar ser merecedora de tal repressão.

Nesse sentido, Warnier (2003, p. 16-17) assevera que:

A identificação individual e coletiva pela cultura tem como corolário a produção de uma alteridade em relação aos grupos cuja cultura é diferente. O contato inter-comunitário suscita reações muitos adversas: idealização do outro, atração pelo exótico, pelo "bom selvagem", mas também desprezo, incompreensão, rejeição, podendo terminar em xenofobia e aniquilamento.

Conforme destacado por vários estudiosos no Brasil, entre eles Paixão (1988); Zaluar (1994); Coelho (2005); Misse (2006); Machado da Silva (2008), o comportamento criminoso não tem uma relação direta com a pobreza.

Contudo, a desigualdade passou a servir de explicação para o fenômeno criminoso, fundamentando-se na nas chamadas "teorias de oportunidade", dentre as quais pode-se destacar a Teoria da Anomia Social proposta por Robert Merton (2004).

Barbosa, Ferreira e Barros (2011, p. 145) afirmam que "em áreas que apresentam urbanização acelerada e desorganizada, e consequentemente alta concentração de moradores nas periferias, aprofunda desigualdade social e a má distribuição de renda geram um quadro de exclusão social".

Adorno (2002, p. 88) afirma que há anos os mapas da violência das capitais brasileiras indicam que as taxas de homicídios eram sempre mais 
elevadas em áreas mais carentes do que nas áreas urbanas, com infraestrutura, oferta de trabalho, lazer e cultura.

\section{A CRIMINALIDADE EM MANAUS DECORRENTE DA IMIGRAÇÃO HAITIANA}

Em meados de abril de 2013 foi realizada uma visita ao escritório da ACNUR em Manaus, onde foram obtidas informações sobre a entrada dos haitianos e a política da ACNUR e relação a refugiados.

No início de maio de 2013 foram feitas duas visitas à Paróquia São Geraldo, onde o pároco residente é quem abraçou a causa de receber os haitianos em Manaus, tratando de obter-lhes comida, teto e trabalho.

A realidade dos grupos de Haitianos que chegavam a Manaus, vindos quase sempre da cidade de Tabatinga (cidade de fronteira), pôde ser observada in loco. Também foram obtidas informações sobre o número de Haitianos atendidos por aquela Paróquia e as demandas para melhorar os serviços humanitários.

Em junho de 2013 foram obtidos os dados da criminalidade no município de Manaus junto à Secretaria de Segurança do Estado, ressaltando-se os principais crimes registrados nas delegacias, no período de janeiro de 2010 à maio de 2013.

Os dados de criminalidade envolvendo Haitianos foram obtidos em dois sistemas independentes, o INFOPOL, que vigorou até 11/03/2012 e o SISP, que passou a operar à partir de 12/03/2012 e vigora até os dias atuais. A coleta dos dados foi realizada de forma independente nos dois sistemas

A coleta e a pesquisa dos dados de criminalidade registrados entre janeiro de 2010 e março de 2012, no sistema INFOPOL, foram realizadas pela Secretaria de Segurança do Estado. Já a coleta e a pesquisa nos dados do SISP, referente ao período entre março de 2012 e maio de 2013, foram realizadas na PRODAM - Processamento de Dados do Amazonas. Esta última etapa foi a mais demorada e somente foi concluída no final de junho de 2013.

A compilação dos dados foi concluída no início do mês de julho/13, e foram obtidos os resultados que estão sintetizados abaixo, nas tabelas que seguem, divididos pelos crimes e contemplando todo o período analisado.

A tabela 01, apresentada a seguir, condensa os dados obtidos dos crimes de maior e menor potencial ofensivo envolvendo cidadãos haitianos na cidade de Manaus. 
Tabela 1 - Ocorrências criminais registradas na cidade de Manaus envolvendo Haitianos no período de Janeiro/2010 a Maio/2013

\begin{tabular}{cccccccc} 
Crime & \multicolumn{2}{c}{ Haitianos no Infopol } & \multicolumn{2}{c}{ Haitianos no SISP } & \multicolumn{2}{c}{ Totais de Haitianos } \\
Vítimas & Autores & Vítimas & Autores & Vítimas & Autores \\
Acidente de Trânsito c/Vítima & 0 & 0 & 1 & 0 & 1 & 0 \\
Acidente de Trânsito s/Vítima & 0 & 0 & 1 & 0 & 1 & 0 \\
Ameaça & 0 & 1 & 6 & 1 & 6 & 2 \\
Apropriação Indébita & 0 & 0 & 0 & 1 & 0 & 1 \\
Calúnia & 0 & 0 & 0 & 2 & 0 & 2 \\
Dano & 0 & 0 & 0 & 1 & 0 & 1 \\
Entorpecentes (tráfico e uso pessoal) & 0 & 0 & 0 & 0 & 0 & 0 \\
Estelionato & 0 & 0 & 5 & 0 & 5 & 0 \\
Extorsão Mediante Sequestro & 0 & 0 & 0 & 1 & 0 & 1 * \\
Furto & 0 & 0 & 24 & 0 & 24 & 0 \\
Homicídio/Latrocínio & 1 & 0 & 0 & 0 & 1 & 0 \\
Injúria & 0 & 0 & 2 & 1 & 2 & 1 \\
Lesão Corporal & 0 & 1 & 6 & 2 & 6 & 3 \\
Outras Ocorrências Não Criminais & 2 & 0 & 12 & 0 & 14 & 0 \\
Perda/Extravio & 9 & 0 & 93 & 0 & 102 & 0 \\
Perturbação do Sossego & 0 & 1 & 0 & 0 & 0 & 1 \\
Roubo & 2 & 0 & 21 & 0 & 23 & 0 \\
Sequestro/Cárcere Privado & 0 & 1 & 0 & 0 & 0 & 1 ** \\
Violência Doméstica & 0 & 0 & 0 & 1 & 0 & 1 \\
Totalização & 14 & 4 & 171 & 10 & $\mathbf{1 8 5}$ & $\mathbf{1 4}$
\end{tabular}

Fonte: Autores. (Elaboração a partir dos dados da pesquisa).

Nota 1: Os crimes cujos campos estão destacados em laranja são considerados de maior potencial ofensivo pela sua maior repercussão na sociedade e por sua contribuição para o aumento da "sensação de insegurança";

Nota 2: Nos crimes restantes, considerados de menor potencial ofensivo, dos 14 registros contendo haitianos com autores, em 9 deles, a vítima também é haitiana;

Nota 3: O valor demarcado com '*' foi desconsiderado porque o autor era um cidadão Angolano e não Haitiano;

Nota 4: O valor demarcado com ' $* *$ ' foi desconsiderado porque a descrição do fato referenciava um "um homem negro que parecia Haitiano";

Observa-se na tabela anterior, que os crimes onde haitianos figuram como autores são: ameaça, apropriação indébita, calúnia, dano, injúria, lesão corporal, perturbação do sossego e violência doméstica. Nos crimes destacados em laranja, isto é, roubos, furtos, entorpecentes (tráfico e uso pessoal), homicídios e latrocínios, não houve a participação de haitianos como autores. 
Ocorreram 199 registros envolvendo haitianos no período analisado, dos quais, 185 registros possuem haitianos figurando como vítimas e 14 registros onde eles figuram como autores. Considerando-se o total de 199 registros como $100 \%$ dos registros envolvendo haitianos, o percentual de haitianos vítimas e autores de crimes, correspondem, respectivamente e aproximadamente, a 93\% e $7 \%$ dos registros.

Os crimes de maior potencial ofensivo, isto é, roubos, furtos, entorpecentes (tráfico e posse para uso pessoal), latrocínios e homicídios, foram analisados individualmente no mesmo período.

A seguir temos a tabela relativa ao crime de roubo, onde encontramos os dados obtidos para o período analisado.

Tabela 2 - Roubos registrados na cidade de Manaus no período de Janeiro de 2010 a Maio de 2013

\begin{tabular}{|ccccc}
\hline Meses/Ano & $\mathbf{2 0 1 0}$ & $\mathbf{2 0 1 1}$ & $\mathbf{2 0 1 2}$ & $\mathbf{2 0 1 3}$ \\
\hline JAN & 1904 & 2020 & 2965 & 2122 \\
FEV & 1734 & 1976 & 2291 & 1916 \\
MAR & 2089 & 2521 & 2259 & 1987 \\
ABR & 1926 & 2341 & 2283 & 2080 \\
MAI & 1928 & 2781 & 2611 & 2216 \\
JUN & 1997 & 2485 & 2228 & -- \\
JUL & 2188 & 2795 & 2247 & -- \\
AGO & 2221 & 3107 & 1894 & -- \\
SET & 2123 & 3055 & 1872 & - \\
OUT & 2050 & 2843 & 1963 & - \\
NOV & 2186 & 2694 & 1767 & -- \\
DEZ & 1798 & 2558 & 1767 & $\mathbf{1 0 3 2 1}$ \\
Totais & $\mathbf{2 4 1 4 4}$ & $\mathbf{3 1 1 7 6}$ & $\mathbf{2 6 1 4 7}$ & $\mathbf{8}$ \\
Haitianos como & $\mathbf{1}$ & $\mathbf{0}$ & $\mathbf{1 4}$ & $\mathbf{0}$ \\
Vítimas & & $\mathbf{0}$ & $\mathbf{0}$ & \\
Haitianos como & $\mathbf{0}$ & & &
\end{tabular}

Fonte: Autores. (Elaboração a partir dos dados da pesquisa).

Observa-se na tabela anterior que 23 haitianos foram vítimas de roubo no período analisado, contudo nenhum haitiano figura com autor deste crime.

A seguir temos a tabela relativa ao crime de furto, onde encontramos os dados obtidos para o período analisado. 
Tabela 3 - Furtos Roubos registrados na cidade de Manaus no período de Janeiro de 2010 a Maio de 2013

\begin{tabular}{|ccccc}
\hline Meses/Ano & $\mathbf{2 0 1 0}$ & $\mathbf{2 0 1 1}$ & $\mathbf{2 0 1 2}$ & $\mathbf{2 0 1 3}$ \\
JAN & 2876 & 3160 & 3680 & 1585 \\
FEV & 2851 & 2928 & 3782 & 2063 \\
MAR & 2968 & 3277 & 3353 & 2862 \\
ABR & 2659 & 3159 & 3557 & 2911 \\
MAI & 3099 & 3443 & 3757 & 2790 \\
JUN & 2950 & 2993 & 2489 & -- \\
JUL & 3003 & 3226 & 2419 & -- \\
AGO & 3245 & 3188 & 3003 & -- \\
SET & 3261 & 2975 & 3301 & -- \\
OUT & 2954 & 2992 & 2945 & -- \\
NOV & 3000 & 3099 & 3101 & -- \\
DEZ & 3190 & 3786 & 2453 & -- \\
\hline Totais & $\mathbf{3 6 0 5 6}$ & $\mathbf{3 8 2 2 6}$ & $\mathbf{3 7 8 4 0}$ & $\mathbf{1 2 2 1 1}$ \\
Haitianos como & $\mathbf{0}$ & $\mathbf{0}$ & $\mathbf{1 6}$ & $\mathbf{8}$ \\
Vítimas & & $\mathbf{0}$ & $\mathbf{0}$ & $\mathbf{0}$ \\
Haitianos como & $\mathbf{0}$ & $\mathbf{0}$ & & \\
Autores & & &
\end{tabular}

Fonte: Autores. (Elaboração a partir dos dados da pesquisa).

Observa-se na tabela anterior que 24 haitianos foram vítimas de furto no período analisado, contudo nenhum haitiano figura com autor deste crime.

A seguir temos a tabela relativa aos crimes de tráfico de entorpecentes e posse de entorpecentes para uso pessoal, onde encontramos os dados obtidos para o período analisado.

Tabela 4 - Crimes de tráfico de entorpecentes e posse de entorpecentes para uso pessoal Roubos registrados na cidade de Manaus no período de Janeiro de 2010 a Maio de 2013

\begin{tabular}{|ccccc} 
Meses/Ano & $\mathbf{2 0 1 0}$ & $\mathbf{2 0 1 1}$ & $\mathbf{2 0 1 2}$ & $\mathbf{2 0 1 3}$ \\
JAN & 157 & 290 & 270 & 382 \\
FEV & 197 & 248 & 274 & 311 \\
MAR & 235 & 246 & 321 & 406 \\
ABR & 195 & 276 & 278 & 441 \\
MAI & 211 & 246 & 296 & 398 \\
JUN & 180 & 228 & 305 & -- \\
JUL & 205 & 231 & 361 & -- \\
AGO & 225 & 182 & 480 & -- \\
SET & 220 & 182 & 413 & -- \\
OUT & 218 & 189 & 332 & -- \\
NOV & 191 & 174 & 339 & -- \\
DEZ & 252 & 259 & 402 & -- \\
Totais & 2486 & 2751 & 4071 & 1938 \\
Haitianos como Vítimas & & Não se aplica * & \\
Haitianos como Autores & $\mathbf{0}$ & $\mathbf{0}$ & $\mathbf{0}$ & $\mathbf{0}$ \\
\hline
\end{tabular}

Fonte: Autores. (Elaboração a partir dos dados da pesquisa). 
Nota: Na classificação "Entorpecentes" estão inseridos os crimes de tráfico de entorpecentes e o de posse de entorpecentes para uso pessoal, nos quais não se enquadram a figura da "vítima", mas tão somente o de "autor".

Observa-se na tabela anterior que nenhum haitiano figura com autor dos crimes de tráfico de entorpecentes ou posse de entorpecentes para uso pessoal.

A seguir temos a tabela relativa aos crimes homicídios e latrocínios, onde encontramos os dados obtidos para o período analisado.

Tabela 5 - Homicídios e latrocínios Roubos registrados na cidade de Manaus no período de Janeiro de 2010 a Maio de 2013

\begin{tabular}{|ccccc|}
\hline Meses/Ano & $\mathbf{2 0 1 0}$ & $\mathbf{2 0 1 1}$ & $\mathbf{2 0 1 2}$ & $\mathbf{2 0 1 3}$ \\
JAN & 74 & 62 & 87 & 52 \\
FEV & 69 & 67 & 75 & 46 \\
MAR & 55 & 81 & 73 & 68 \\
ABR & 54 & 71 & 95 & 57 \\
MAI & 57 & 73 & 101 & 71 \\
JUN & 63 & 81 & 84 & -- \\
JUL & 52 & 83 & 106 & -- \\
AGO & 67 & 86 & 81 & -- \\
SET & 65 & 84 & 73 & -- \\
OUT & 78 & 87 & 64 & -- \\
NOV & 88 & 96 & 74 & -- \\
DEZ & 70 & 95 & 73 & -- \\
\hline Totais & $\mathbf{7 9 2}$ & $\mathbf{9 6 6}$ & $\mathbf{9 8 6}$ & $\mathbf{2 9 4}$ \\
Haitianos como Vítimas & $\mathbf{0}$ & $\mathbf{0}$ & $\mathbf{1}$ & $\mathbf{0}$ \\
\hline Haitianos como Autores & $\mathbf{0}$ & $\mathbf{0}$ & $\mathbf{0}$ & $\mathbf{0}$ \\
\hline
\end{tabular}

Fonte: Autores. (Elaboração a partir dos dados da pesquisa).

Observa-se na tabela anterior, que um haitiano foi vítima de homicídio no período analisado, contudo, nenhum haitiano figura com autor deste crime ou do crime de latrocínio. 


\section{CONSIDERAÇÕES FINAIS}

A chegada dos haitianos na cidade de Manaus gerou muitas polêmicas, inclusive a de que se daria o aumento da criminalidade em decorrência da presença deles, na cidade. Nos crimes de maior potencial ofensivo, ou seja, roubos, furtos, tráfico de drogas, posse de entorpecentes, latrocínios e homicídios, no período analisado (Janeiro de 2010 a Maio de 2013), chegouse à conclusão de que não houve a participação dos haitianos como autores destes crimes.

A questão inicial levantada neste estudo, isto é, se a massa de haitianos que imigrou para Manaus afetou os índices de criminalidade da cidade, foi assim respondida com uma negativa, pois, não houve a participação dos haitianos como autores dos crimes de maior potencial ofensivo, considerados assim pela sua repercussão na sociedade.

Do total de registros no período analisado que envolviam haitianos, 199 registros, todos referiam-se a crimes de menor potencial ofensivo. Ainda assim, dos 199 registros encontrados, em 185 registros eles figuram como vítimas, correspondendo, portanto, a 93\% dos registros envolvendo haitianos no período analisado.

Concluiu-se também que, mesmo nos crimes de menor potencial ofensivo, considerados assim pela sua baixa repercussão na sociedade, onde haitianos figuram como autores, correspondentes a 14 registros no período analisado, a proporção destes crimes em relação ao total registrado no mesmo período, torna-os matematicamente desprezíveis. Destaca-se ainda que, nestes 14 registros de crimes de menor potencial ofensivo, em 9 deles (64\%), vítima(s) e autor(es) são haitianos.

Apesar da intolerância de parte da população manauara em aceitar a presença dos haitianos na cidade, explicitada nas matérias jornalísticas do período, apesar da preocupação da população em proteger os escassos empregos de Manaus para os brasileiros, apesar do preconceito social, apesar da literatura indicar a desigualdade social como fator determinante para o aumento da criminalidade, os números desta pesquisa demonstraram que os haitianos não aumentaram os índices de criminalidade da cidade.

Mesmo com a grande massa de haitianos residente na cidade, que iniciou em 2010 com a chegada dos primeiros imigrantes, até os dias atuais, 
os números indicam que estas pessoas estão em na cidade de Manaus para trabalhar, e em sua grande maioria, alheias à criminalidade. E mais, a análise dos registros dos crimes de maior potencial ofensivo, que contribuem mais para o aumento da "sensação de insegurança", nestes, não houve a participação dos haitianos. Enfim, eles vieram em paz. Que o Brasil possa fazer prevalecer os direitos humanos e a dignidade da pessoa humana a esse povo que vem em busca de asilo ambiental.

\section{REFERÊNCIAS}

ACNUR. Colóquio sobre Proteção Internacional dos refugiados na América Central, México e Panamá: Problemas Jurídicos e Humanitários. Cartagena, 1984.

ADORNO, Sergio. Exclusão socioeconômica e violência urbana. Sociologias, Porto Alegre, ano 4, n. 8, p. 84-135, 2002.

ADORNO, Sérgio. Violência e Racismo. Discriminação no acesso à justiça penal. In SCHWARTZ, Lília; QUEIROZ, Renato da Silva. Raça e Diversidade. São Paulo: EDUSP, 1995.

ALVES. José Augusto Lindgren. Os direitos humanos como tema global. São Paulo: Perspectiva, 1994.

ANDRADE, José Henrique Fischel de. Direito internacional dos refugiados: evolução histórica (1921-1952). Rio de Janeiro: Renovar, 1996.

BARBOSA, Andréa M. F; FERREIRA, Luiz O. C; BARROS, Maria D. A. Homicídios e condição de vida: a situação na cidade do Recife, Pernambuco. Epidemiol. Serv. Saúde, Brasília, v. 20, n. 2, p. 141-150, 2011.

BRASIL. Constituição (1988). Constituição da República Federativa do Brasil. Brasília: Congresso Nacional, 1988. 
BRASIL. Decreto $n^{\circ} 50.215$, de 28 de janeiro de 1961. Promulga a Convenção relativa ao Estatuto dos Refugiados, Genebra, 28 de julho de 1951. Diário Oficial da República Federativa do Brasil, Brasília, 28 jan. 1961.

COELHO, Edmundo C. Oficina do Diabo e outros estudos sobre criminalidade. Rio de Janeiro: Record, 2005.

D'ADESKY, Jacques. Imigração interna e controle de estrangeiros: O discurso nacionalista e a prática da exclusão social. In: SEMINÁRIO INTERNACIONAL: as minorias e o direito, 2003, Brasília. Brasília: Conselho da Justiça Federal, 2003. v. 24.

DEL'OLMO, Florisbal de Souza. Curso de Direito Internacional Público. Rio de Janeiro: Forense, 2009.

GODOY, Gabriel Gualano de. O caso dos haitianos no Brasil e a via da proteção humanitária complementar. In: RAMOS, André de Carvalho et al. (Org.). 60 anos de Acnur: Perspectivas de futuro. São Paulo, 2011.

IDOETA, Paula Adamo. Controle migratório de haitianos no Brasil gera debate. $B B C$ Brasil, São Paulo, 12 jan. 2012. Disponível em: $<$ http:// www.bbc.co.uk/portuguese/ noticias/2012/01/ 120111_haitianos_imig_pai.shtml>.Acesso em: 12 jul. 2013.

LOPES NETO, A. A. Bullying - comportamento agressivo entre estudantes. J Pediatr., Rio de Janeiro, v.81, n. 5, p. 164-172, 2005.

MACHADO DA SILVA, Luiz Antônio. Vida sob cerco: violência e rotina nas favelas do Rio de Janeiro. Rio de Janeiro: Nova Fronteira, 2008.

MERTON, Robert K. Social Structure and Anomie. In: JACOBY, Joseph. Classics of Criminology. Long Grove, Waveland, 2004. Cap. 27, p. 214-223. 
MISSE, Michel. Crime e Violência no Brasil Contemporâneo: estudos de sociologia do crime e da violência urbana. Rio de Janeiro, Lumen Júris, 2006.

ORGANIZAÇÃO DAS NAÇÕES UNIDAS. Acnur promove debate em Brasília sobre deslocamentos forçados por questões ambientais. Brasília, 2012.

PAIXÃO, Antônio L. Crime, Controle Social e Consolidação da Democracia: as metáforas da cidadania. In: REIS, Fabio W;

O’DONNEL, Guillermo (Org.). A Democracia no Brasil: dilemas e perspectivas. Rio de Janeiro: Vértice, 1988.

RAMOS, Érika Pires. Refugiados Ambientais: em busca de reconhecimento pelo Direito Internacional. 2011. Tese (Doutorado em Direito) - Universidade de São Paulo, São Paulo, 2011.

REZEK, José Francisco. Direito Internacional Público. 10. ed. São Paulo: Saraiva, 2007.

SARLET, Ingo Wolfgang. Dignidade da pessoa humana e direitos fundamentais. 4. ed. Rio Grande do Sul: Advogados, 2006.

SOARES, Guido Fernando Silva. Curso de Direito Internacional Público.

2.ed. São Paulo: Atlas, 2004. v.1.

VARELLA, Marcelo Dias. Direito Internacional Público. São Paulo: Saraiva, 2009.

WARNIER, Jean-Pierre. A mundialização da cultura. Bauru: EDUSC, 2003.

ZALUAR, Alba. Condomínio do Diabo. Rio de Janeiro: Revan 1994. 
ZALUAR, Alba. Violência e crime. In: Miceli, S. (ed.). O que ler nas ciências sociais no Brasil (1970-1995). São Paulo: Sumaré, ANPOCS, 1999. p. 13-107.

Artigo recebido em: 01/10/2013 Aprovado para a publicação em: 12/11/2013

Como citar: TAMER, Alexandre dos Santos. POZZETI, Valmir César. A Imigração Haitiana e a criminalidade no Município de Manaus. Revista do Direito Público. Londrina, v.8, n.3, p.55-76, set./dez. 2013. DOI: 10.5433/ 1980-511X.2013v8n3p55. 